\title{
BMJ Open 'Please don't call me Mister': patient preferences of how they are addressed and their knowledge of their treating medical team in an Australian hospital
}

\author{
Shaun R Parsons, ${ }^{1}$ Andrew J Hughes, ${ }^{2}$ N Deborah Friedman ${ }^{1}$
}

To cite: Parsons SR, Hughes AJ, Friedman ND. 'Please don't call me Mister': patient preferences of how they are addressed and their knowledge of their treating medical team in an Australian hospital. BMJ Open 2016;6: e008473. doi:10.1136/ bmjopen-2015-008473

- Prepublication history for this paper is available online. To view these files please visit the journal online (http://dx.doi.org/10.1136/ bmjopen-2015-008473)

Received 2 May 2015

Revised 20 August 2015 Accepted 15 September 2015

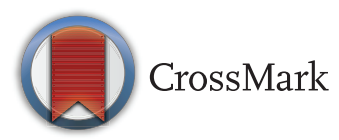

${ }^{1}$ Department of General Medicine, University Hospital Geelong, Barwon Health, Geelong, Victoria, Australia ${ }^{2}$ Department of General Medicine, Deakin University Medical School, University Hospital Geelong, Barwon Health, Geelong, Victoria, Australia

Correspondence to Dr Shaun Parsons; shaun.r.parsons@gmail.com

\section{ABSTRACT}

Objectives: To investigate how patients prefer to be addressed by healthcare providers and to assess their knowledge of their attending medical team's identity in an Australian Hospital.

Setting: Single-centre, large tertiary hospital in Australia.

Participants: 300 inpatients were included in the survey. Patients were selected in a sequential, systematic and whole-ward manner. Participants were excluded with significant cognitive impairment, non-English speaking, under the age of 18 years or were too acutely unwell to participate. The sample demographic was predominately an older population of Anglo-Saxon background.

Primary and secondary outcome measures:

Patients preferred mode of address from healthcare providers including first name, title and second name, abbreviated first name or another name. Whether patients disliked formal address of title and second name. Secondarily, patient knowledge of their attending medical team members name and role and if correct, what position within the medical hierarchy they held.

Results: Over $99 \%$ of patients prefer informal address with greater than one-third having a preference to being called a name other than their legal first name.

$57 \%$ of patients were unable to correctly name a single member of their attending medical team.

Conclusions: These findings support patient preference of informal address; however, healthcare providers cannot assume that a documented legal first name is preferred by the patient. Patient knowledge of their attending medical team is poor and suggests current introduction practices are insufficient.

\section{BACKGROUND}

Successful doctor-patient communication remains central to the establishment of a therapeutic doctor-patient relationship. The function of communication is to gather information, define therapeutic outcomes, and build a caring and supportive relationship with patients. ${ }^{1}$ Effective communication also

\section{Strengths and limitations of this study}

- Main findings appropriately addressed intended aims.

- Significant results which can readily be addressed by instituting a change of practice in administration, daily patient communication and training of junior medical staff.

- Patient-centred research intended to improve patient's experience while in hospital.

- Single centre and predominantly Anglo-Saxon demographic.

- No control for age or clinical condition of the patient.

provides the physician with the opportunity to improve patient satisfaction thereby facilitating improved health outcomes. ${ }^{2}$ The manner in which a doctor greets their patient is an influential aspect in establishing an effective and supportive rapport and provides the foundation of a satisfying patient experience. ${ }^{3-5}$

Ethnic and cultural factors can influence preferred modes of address. This has been demonstrated in Israel, ${ }^{6} \operatorname{Iran}^{7}$ and in African-Americans in the $\mathrm{USA}^{8}{ }^{8}$ where formal address by title and surname name is preferred. In contrast, in an Irish geriatric unit $^{9}$ and also in a general practice setting in the $\mathrm{UK},{ }^{10}$ the majority of patients preferred first name greetings.

In the Australian setting, there has been limited research completed in this area. One study in general practice demonstrated that $90 \%$ of patients prefer to be addressed by their first name only and $3.4 \%$ prefer to be addressed by another name. ${ }^{11}$ Established relationships between the doctor and patient was identified as a common factor which influenced the level of formality the patient was comfortable with, ${ }^{11}$ this may not be applicable in the acute hospital environment 
where such established relationships may not exist. The only other Australian study in 1994 found that $83 \%$ of patients preferred informal address across inpatient and private outpatient settings. ${ }^{12}$

In our hospital setting, the number of patients who prefer to be addressed by a name other than their legal name is not known. This may include an abbreviation of their first name or a different name entirely. Patients in hospital may be addressed by their legal name by default, as it appears on their medical record, yet may not be a name that they are known by. This was highlighted in a piece in JAMA, where use of a legal name was interpreted as a lack of personal interest in patients, creating an atmosphere of disconnect. ${ }^{13}$

Patients in hospital both need and should know the name and position of the person or people providing their medical care. Ensuring a patient's knowledge of the caregivers name is significant in initiating and maintaining a positive therapeutic partnership with the patient. ${ }^{14}$ Knowledge of the physicians' role on the attending team has been commonly associated with patient satisfaction ${ }^{15}{ }^{16}$; however, in one study in the UK, only the minority of patients knew the name of their attending consultant. ${ }^{17}$ This may be more prominent in teaching hospitals where changes in personnel occur more frequently. ${ }^{18}$ In Australia, the knowledge patients have of their attending medical team has not been studied before.

Currently, newly admitted patient's names are automatically populated onto hospital admission records from an Australian Government issued healthcare card such as a Medicare card. Patients are not routinely questioned how they wished to be addressed by hospital staff or if their legal first name is their preferred name. Hospital policy defines that name badges or identification (ID) cards are provided to all staff; however, they may not displayed in a standardised visible manner with many staff choosing to attach the ID to a poorly visible location, such as their waist belt. There is no policy regarding how hospital staff must introduce themselves to patients.

The setting for this research was a 450 bed tertiary teaching hospital in Australia. The different aims of this study were to identify what mode of address patients in an Australian hospital prefer, what proportion of patients wish to be called a name other than their legal names and the number of patients who could correctly name any member of their attending medical team.

\section{METHODS}

\section{Survey tool}

A survey was designed and piloted to assess inpatient preferences of address and knowledge of their attending medical team. The survey was administered face-to-face with the primary researcher entering the participant's responses directly to SurveyMonkey ${ }^{19}$ through a tablet PC. Questions included: What name do you prefer to be addressed by while in hospital? Do you object to being addressed as $\mathrm{Mr} / \mathrm{Mrs} / \mathrm{Ms}$ (Surname)? Are you able to tell me the name of any of your treating doctors? If yes-do you know their role/position on the medical team?

Additional patient characteristics were recorded including age, gender and whether they were a medical or surgical admission.

Responses to questions about preferred names were compared against hospital admission details of names and classified as: a legal first name, title and surname, abbreviation of first name or other name. Responses to naming their treating medical team were compared against the patients' allocated medical unit or through examining the patient's record.

\section{Patient recruitment}

Inpatients at this institution were approached during the month of October 2014 and invited to participate in a survey administered by the primary researcher. Patients were selected in a sequential, systematic and whole-ward manner. Patients were excluded from participation if they had known cognitive impairment (including dementia and delirium), were non-English speaking, were under the age of 18 years or were too acutely unwell to participate. Prior to approaching a patient, their medical record was assessed for diagnoses of cognitive impairment that was then confirmed with the patient's primary nurse. Verbal informed consent was obtained from all participants. The study was unfunded and approved by the Barwon Health Research and Ethics Committee.

\section{Data collection and management}

Data collected during the survey was entered directly into SurveyMonkey by the primary researcher via a tablet PC. Results were tabulated and analysed with descriptive statistics using the SurveyMonkey web-based analytical tools.

\section{RESULTS}

Three hundred and fifty-five inpatients were approached to be included in the survey over a 1-month period. Fourteen patients refused to participate in the study and 41 met the exclusion criteria resulting in 300 participants included in the final sample. The majority of respondents were over 60 years of age with a slight male predominance (table 1). Our sample was consistent with the age of general medical patients at our institution. When correlated to the Australian Institute of Health and Welfare published statistics on Australian hospital population demographics, our sample was comparable but with a greater proportion of patients over 60 years. ${ }^{20}$

Approximately one-third of patients preferred to be addressed by a name other than their legal name; $22.6 \%$ preferred an abbreviation of their first name and $11.6 \%$ wished to be called by another name entirely. 
Table 1 Characteristics of survey respondents $(\mathrm{N}=300)$

\begin{tabular}{lc}
\hline Characteristic of respondents & Frequency (\%) \\
\hline Age (years) & \\
$18-30$ & $16(5.3)$ \\
$31-45$ & $20(6.7)$ \\
$46-60$ & $47(15.7)$ \\
$61-75$ & $108(36)$ \\
$76+$ & $109(36.3)$ \\
Gender & \\
Male & $171(57)$ \\
Female & $129(43)$ \\
Admission & \\
Medical & $149(49.7)$ \\
Surgical & $151(50.3)$ \\
\hline
\end{tabular}

Preference for a name other than their legal name was much more common in the older male demographic, with $88.5 \%$ being over 61 years and $71.4 \%$ male. An abbreviated first name was preferred across the sample demographic and did not demonstrate age bias. Less than $1 \%$ of inpatients opted for formal address by title and surname (figure 1).

Formal address (eg, as $\mathrm{Mr}$ or Mrs) was disliked by $58.7 \%$ of surveyed patients. This was more common among men $(63.6 \%)$ and there was no age bias with this opinion being shared by all age groups in the overall sample.

The majority of patients $(57.3 \%)$ were unable to name a member of their attending medical team. Of those who were able to name any treating of their doctors, $24.7 \%$ could name one, $10 \%$ could name two and only $8 \%$ could name three or more (table 2). Surgical patients performed better than medical with $47 \%$ of surgical patients able to name one or more attending doctors compared with $38.9 \%$ of medical patients. When the patient could nominate their medical caregiver(s) names, they were most commonly correct $(86.7 \%)$.

In response to identifying the respective roles of correctly named doctors on the team, $20.3 \%$ were unaware of their position. Correct identification of the doctors' name and role was overwhelming for the attending

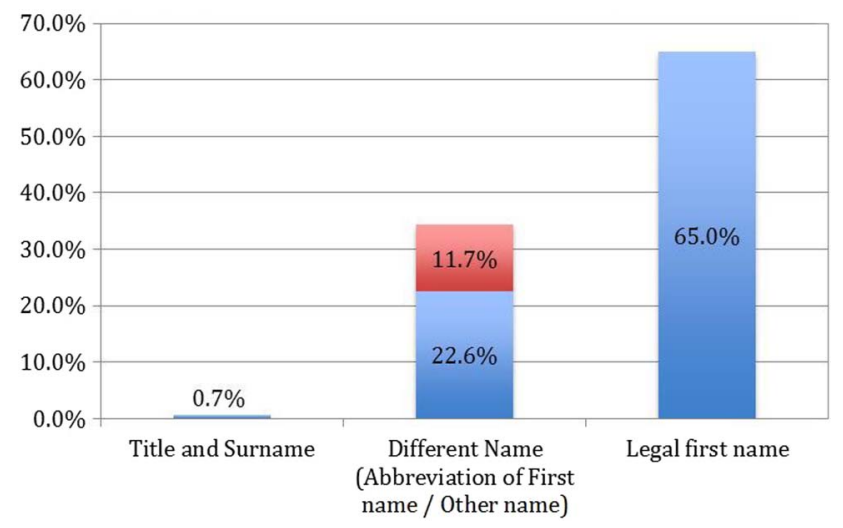

Figure 1 Patient preferences for mode of address. consultant $(95.9 \%)$, followed by the registrar/fellow $(22.5 \%)$. Junior doctors were poorly identified with $5.1 \%$ naming the resident and no respondents correctly recalled the intern's name and role.

\section{DISCUSSION}

The acute hospital setting is a unique environment with regard to dialogue between patients and healthcare workers. Patients are acutely unwell, vulnerable, seen by healthcare workers multiple times in a day and often given critical information about the state of their health by a group of strangers. Different from outpatient medical consulting settings where one doctor will see one patient at a time, the busy hospital environment does not usually foster the development of rapport. Central to the development of doctor-patient rapport is the respectful way in which patients are addressed by a name which they prefer. The reciprocal of this, and equally as important, is the knowledge that patients have of their treating medical team.

This short survey of hospital inpatients revealed that over one-third of patients prefer to be addressed by a name other than their legal first name. This was predominantly demonstrated in males over 61 years; however, it was seen throughout all demographics. This area has limited prior research with one article in an Australian general practice setting finding the incidence of patient preference for a name other than their legal names was much lower at $3.8 \% .^{11}$ One possible approach to ensuring that patients are addressed according to their preference is to question the patient about their preferred name during their initial presentation to a health service. This information should be both stored in the patient medical record and displayed, so that it is easily identified by other healthcare workers, for example, above the patient's bed.

Inpatients in this Australian hospital overwhelmingly preferred informal modes of address. This result supports previous data from Australia ${ }^{11} 12$ and findings from overseas. ${ }^{8921}$ Over half of the surveyed patients expressed a dislike for formal address with common responses including 'feels too impersonal' and 'that is my father's name'.

Table 2 Patient knowledge of treating medical teams' identity and role

Question

Frequency (\%)

Number of treating doctors names recalled $(\mathrm{N}=300)$

0

$172(57.3)$

1

2

3

$74(24.7)$

$30(10)$

$24(24)$

Accuracy of recalled name $(\mathrm{N}=128)$

All correct

Partially correct ${ }^{\star}$

$111(86.7)$

Incorrect

$6(4.7)$

$11(8.6)$

${ }^{*}$ Multiple responses where one was correct and one or more were incorrect. 
It highlights the informal attitude seen in Australia culture, which has been linked to the egalitarian ethos held in our society. ${ }^{22}$ We suspect this may not be generalisable to other countries and cultures.

This survey revealed that patient's knowledge of their attending medical team was poor with the majority of patients being unable to name a single member of their treating medical team. This outcome correlates with prior international evidence. ${ }^{14}{ }^{17}$ This implies that doctors in our setting have not properly introduced themselves or have relied solely on verbal introductions, which patients tend to not be able to recall. The result is that patients are receiving information and acute medical care from persons with whom they have little or no rapport. When the physicians name and role were correctly recalled, only $5 \%$ were junior doctors. This is surprising given that junior medical staff commonly have more contact with the patient ${ }^{23}$ and suggests this group of doctors should significantly improve the way they introduce themselves to patients.

Providing the patient with an information sheet or card on admission that defines the attending medical team members name and role, and wearing a name badge in a visible location could improve patients' ability to recall names and create a greater sense of familiarity with their treating team.

There are several limitations of this study. First, it was undertaken at a single site, and there may be local and regional differences in the way that patients and medical teams interact that may affect generalisability. Second, our hospital has a Caucasian and Anglo-Saxon predominant demographic, which would affect patients' preferences with regard to mode of address. Finally, patients were not asked about their knowledge of their treating nursing or allied health staff, and it is possible that patients may have better knowledge of these members of the healthcare team.

\section{CONCLUSIONS}

Our findings support patient preference for informal greetings from their healthcare providers; however, it highlights that it is not safe to assume that a legal first name would be preferred. Patient knowledge of their attending medical team was poor suggesting current practices of introduction are insufficient. A practical approach for improvement would be for doctors to introduce themselves at first meeting with their full name and role on the team, name of the attending consultant and then ask the patient's preferred name of address. We propose that these findings may be applicable at other health services.

Contributors SRP, AJH and NDF were involved in study concept and design, manuscript drafting and editing. SRP was involved in data collection and data analysis.
Funding This research received no specific grant from any funding agency in the public, commercial or not-for-profit sectors.

Competing interests None declared.

Ethics approval Barwon Health Human Research Ethics Committee

Provenance and peer review Not commissioned; externally peer reviewed.

Data sharing statement Extra data can be accessed via the Dryad data repository at http://datadryad.org/ with the doi:10.5061/dryad.75777.

Open Access This is an Open Access article distributed in accordance with the Creative Commons Attribution Non Commercial (CC BY-NC 4.0) license, which permits others to distribute, remix, adapt, build upon this work noncommercially, and license their derivative works on different terms, provided the original work is properly cited and the use is non-commercial. See: http:// creativecommons.org/licenses/by-nc/4.0/

\section{REFERENCES}

1. Ha JF, Longnecker N. Doctor-patient communication: a review. Ochsner J 2010;10:38-43.

2. Herndon JH, Pollick KJ. Continuing Concerns, new challenges, and next steps in physician-patient communication. J Bone Joint Surg Am 2002;84:309-15.

3. Kahn MW. Etiquette-based medicine. N Engl J Med 2008;358: 1988-9.

4. Lavin M. What doctors should call their patients. J Med Ethics 1988;14:129-31.

5. Comstock LM, Hooper EM, Goodwin JM, et al. Physician behaviors that correlate with patient satisfaction. J Med Educ 1982;57:105-12.

6. DeKeyser FG, Wruble AW, Margalith I. Patients voice issues of dress and address. Holist Nurs Pract 2003;17:290-4.

7. Najafi M, Khoshdel A, Kheiri S. Preferences of Iranian patients about style of labelling and calling of their physicians. J Pak Med Assoc 2012;62:668-71

8. Makoul G, Zick A, Green M. An evidence-based perspective on greetings in medical encounters. Arch Intern Med 2007;167:1172-6.

9. Tiernan E, White $\mathrm{S}$, Henry $\mathrm{C}$, et al. Do elderly patients mind how doctors address them? Ir Med $J$ 1993;86:73.

10. McKinstry B. Should general practitioners call patients by their first names? BMJ 1990;301:795-6.

11. Moore R, Yelland M, Ng SK. Moving with the times-familiarity versus formality in Australian general practice. Aust Fam Physician 2011;40:1004-7.

12. Stewart-Wynne EG, Tey LY, Marshall JA, et al. How do patients like to be addressed by hospital staff? Med J Aust 1997;166:224.

13. Stapleton F. MY name is jack. JAMA 2000;284:2027-7.

14. Brockopp DY, Franey BN, Sage-Smith D, et al. Patients' knowledge of their caregivers' names. A teaching-hospital study. Hosp Top 1992;70:25-8

15. Santen SA, Hemphill RR, Prough EE, et al. Do patients understand their physician's level of training? A survey of emergency department patients. Acad Med 2004;79:139-43.

16. Malcolm CE, Wong KK, Elwood-Martin R. Patients' perceptions and experiences of family medicine residents in the office. Can Fam Physician 2008;54:570-1, 71.e1-6.

17. Pittman MA, Aggarwal G, Shee CD. Do medical patients know the name of their consultant? Clin Med 2009;9:633-4

18. Fleming GV. Hospital structure and consumer satisfaction. Health Serv Res 1981;16:43-63.

19. SurveyMonkey. Free online survey software \& questionnaire tool: SurveyMonkey. 2014 cited 6 November 2014. https://www. surveymonkey.net/

20. Australian Institute of Health and Welfare. Australia's hospitals 2012-13 at a glance. Health services series no. 55. Cat. no. HSE 146. Canberra: AlHW, 2014.

21. Lill MM, Wilkinson TJ. Judging a book by its cover: descriptive survey of patients' preferences for doctors' appearance and mode of address. BMJ 2005;331:1524-7.

22. Wierzbicka A. Cross-cultural pragmatics: the semantics of human interaction. Mouton de Gruyter, 2003.

23. Dalia S, Schiffman FJ. Who's my doctor? First-year residents and patient care: hospitalized patients' perception of their "main physician". J Grad Med Educ 2010;2:201-5. 